\title{
Optimal Controller Design for a Turbogenerator Automatic Voltage Regulator and Governor using Two Degree of Freedom Linear Quadratic Gaussian (2DOFLQG)
}

\author{
Firas M. Tuaimah \\ University of Baghdad \\ Baghdad, Iraq
}

\author{
Nihad M. Al-Rawi \\ University of Baghdad \\ Baghdad, Iraq
}

\author{
Waleed A. Mahmoud \\ University of Baghdad \\ Baghdad, Iraq
}

\begin{abstract}
This paper introduces a computational methodology that adopted a method of Linear Quadratic Gaussian (LQG) controller as Automatic Voltage Regulator (AVR) and Governor to control the generator terminal voltage and the turbine speed. In this method the models were assumed to be Linear, depending on this method the controller power consumption was minimized depending on some performance index, which is assumed to be Quadratic. This method was taken into account the noise and the disturbance in view, considered its distribution as Gaussian. The two degree of freedom (2DOF) structure was adopted, in which two controllers are used. The effectiveness of the proposed control action is demonstrated through some computer simulations on a Single-Machine Infinite- Bus (SMIB) power system.

To accommodate stability requirements, a mathematical model for the generator and the turbine was derived based on the twoaxis theorem and starting from the swing equation. Results obtained show that adopting such a controller enhanced the steady state and transient stability.
\end{abstract}

\section{Keywords}

LQG control, generator and turbine modeling, two degree of freedom, damping torque

\section{INTRODUCTION}

The oldest power generating plants were supplied with continuously acting automatic voltage regulators.

When the number of power plants with AVR increased, it became obvious that the high performance of these voltage controllers or regulators had a destabilizing effect on the power system. Power oscillations of small magnitude and low frequency often sustained for long durations of time. In some cases, this presented a restriction on the amount of power that can be transmitted within the system. Power system stabilizers were developed to add damping torque coefficients of these power oscillations by modulating the excitation supplied to the synchronous machine [1].

The prime mover plays an essential role in causative to the stability of the whole system. Optimum transient response of a closed loop control system to an external disturbance depends not just on the transfer function of the excitation controller, generator and sensors but also the speed/load controller as well [2].

Keeping frequency within adequate limits requires to continuously maintaining a balance between resources and loads. This security action is performed by the Load Frequency
Control (LFC). The LFC induces output variations to generating units, through the operation of Speed Governor, Automatic Generation Control (AGC) and through operator actions [2].

Latest efforts in designing the power system controllers are based on some adaptive and optimal control techniques like

Artificial Neural Network (ANN), Fuzzy logic, Genetic algorithm, Pole placement, Linear Quadratic Regulator (LQR) and on the robust controllers like LQG (H2) and (Hळ).

R. Asgharian and D.C. Macdonald [3] suggested an optimal linear control system for designing auxiliary signal controllers for turbine generators. The design take into the concern the torsional mode oscillation of the rotor to obtain the best performance.

Ranjan Vepa [4] proposed a nonlinear rotor-side controller (RSC) for a wind turbine generator based on nonlinear, LQG optimal control theory. The goal is to express the synthesis of a maximum power point tracking.

Youssef A. Smailli and Ali T. Alouani [5] investigates the application of H-infinity optimal control theory for designing the supplementary excitation and governor control system to improve the stability and performance robustness of an electric power system.

M. Djukanovic et. al. [6] presents a design technique of a new adaptive optimal controller of the low head hydropower plant using artificial neural networks (ANN). Results obtained on the non-linear mathematical model demonstrate that the effects of the NNC closely agree with those obtained using the state-space multivariable discrete-time optimal controllers.

F. Fatehi et.al. [7] presents a combined system identification and controller design methods to dampen low-frequency oscillations in multimachine power systems with Linear quadratic Gaussian controller design with loop transfer recovery.

Gui-chen Zhang [8] proposed an LQG control scheme for output power leveling with unknown dynamics for running of unstable speed exhaust turbine generator using main engine waste heat by high turbulence intensities,

Feilat and Younan [9] Presents an on-line optimal approach for dynamic stability assessment of single-machine infinite-bus system. The approach is based on estimating the synchronizing and damping torque Coefficients of the synchronous machine. The coefficients are estimated from the time responses of the changes in the rotor angle, rotor speed, and electromagnetic torque. These coefficients can be used as indices to provide 
insight into the relative stability of the synchronous machine. This approach results in a remarkable reduction in the computational complexity associated with this problem and hence allow for on-line implementation needed for continuous monitoring of the dynamic stability indices.

T. C. Yang et al. [10] designed a decentralized robust load frequency control (LFC) for interconnected power system. This design based on a new Linear Quadratic Regulator design approach.

The interest in designing the optimal and robust controllers has increased tremendously in the last few years because of its rigidity and stability.

In this paper, a mathematical model or a state equation of the turbine and the generator in its standard form has been developed, which is based on the two-axis theorem and starting from the swing equation. This model can be used to simulate the machine behavior under healthy (steady-state) and faulty conditions (transient-state).

\section{SOFTWARE IMPLEMENTATION}

In this paper to investigate the effectiveness of adopting the LQG controller as AVR and as Governor, the conventional AVR and the conventional Governor was also adopted for comparison. The two degree of freedom 2DOF structure was used in designing the LQG controller. Controller performance will be expressed in terms of performance indices used in feedback control system theory. A 555MW turbogenerator whose details are given in the Appendix A is taken as an example to which the software is employed.

\section{TURBINE \& GENERATOR \\ MATHEMATICAL MODELLING}

Depending on the swing equation viewpoint which is the equations of central importance in power system stability analysis are the rotational inertia equation describing the effect of unbalance between the electromagnetic torque and the mechanical torque of the individual machines.[2]

When there is un unbalance between the torque acting on the rotor, the net torque causing acceleration (or deceleration) is

$T_{a}=T_{m}-T_{e}$

The combined inertia of the generator and prime mover is accelerated by the unbalance in the applied torques. Hence, the equation of motion is:

$J \frac{d \omega_{m}}{d t}=T_{a}=T_{m}-T_{e}$

The swing equation then can be expressed as two first order differential equations, becomes

$$
\begin{aligned}
& \frac{d\left(\Delta \omega_{r}\right)}{d t}=\frac{1}{2 H}\left(\bar{T}_{m}-\bar{T}_{e}-K_{D} \Delta \bar{\omega}_{r}\right) \\
& \frac{d \delta}{d t}=\omega_{o} \Delta \bar{\omega}_{r}
\end{aligned}
$$

The block diagram form representation of equations 3 and 4 is shown in Figure 1.

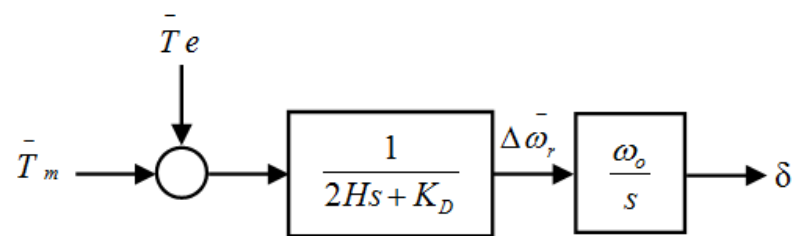

Fig. 1 Block diagram representation of swing equations

Linearizing and writing (3) and (4) in the vector-matrix form, obtain

$\frac{d}{d t}\left[\begin{array}{c}\Delta \omega_{r} \\ \Delta \delta\end{array}\right]=\left[\begin{array}{cc}\frac{-K_{D}}{2 H} & \frac{-K_{S}}{2 H} \\ \omega_{o} & 0\end{array}\right]\left[\begin{array}{c}\Delta \omega_{r} \\ \Delta \delta\end{array}\right]+\left[\begin{array}{c}\frac{1}{2 H} \\ 0\end{array}\right] \Delta T_{m}$

where

$K_{S}=$ Synchronizing torque coefficient in pu torque/rad

$K_{D}=$ Damping torque coefficient in pu torque/pu speed deviation

$H=$ Inertia constant in MW.s/MVA

$\Delta \omega_{\mathrm{r}}=$ Speed deviation in $\mathrm{pu}=\left(\omega_{\mathrm{r}}-\omega_{\mathrm{o}}\right) / \omega_{\mathrm{o}}$

$\Delta \delta=$ Rotor angle deviation in elect.rad

$\omega_{0}=$ Rated speed in elect.rad $/ \mathrm{s}=2 \pi f_{o}=314$ for a $50 \mathrm{~Hz}$ system.

Depending on the previous derivations, and inserting the effect of the exciter, then complete model for the exciter-generator can be given as below in Figure 2.

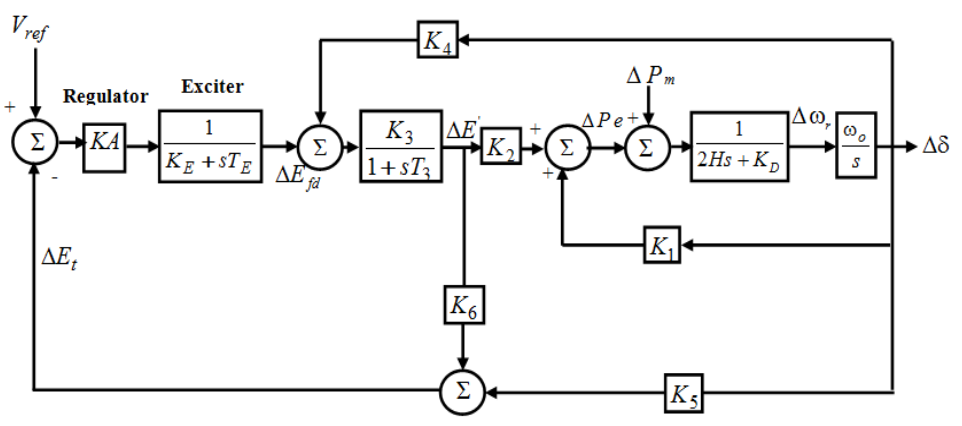

Fig. 2 Exciter generator model

In the vector-matrix form, the effect of excitation circuit can be given as follows, which represents the whole matrix of excitergenerator

$$
\frac{d}{d t}\left[\begin{array}{c}
\Delta \omega_{r} \\
\Delta \delta \\
\Delta E^{\prime} \\
\Delta E_{f d}
\end{array}\right]=\left[\begin{array}{cccc}
\frac{-K_{D}}{2 H} & \frac{-K_{1}}{2 H} & \frac{-K_{2}}{2 H} & 0 \\
\omega_{0} & 0 & 0 & 0 \\
0 & \frac{-K_{3} K_{4}}{T_{3}} & \frac{-1}{T_{3}} & 0 \\
0 & \frac{-K A K_{5}}{T_{E}} & \frac{-K A K_{6}}{T_{E}} & \frac{-K_{E}}{T_{E}}
\end{array}\right]\left[\begin{array}{c}
\Delta \omega_{r} \\
\Delta \delta \\
\Delta E^{\prime} \\
\Delta E_{f d}
\end{array}\right]+\left[\begin{array}{cc}
\frac{1}{2 H} & 0 \\
0 & 0 \\
0 & \frac{K A}{T_{E}}
\end{array}\right]\left[\begin{array}{l}
\Delta P_{m} \\
V_{r e f}
\end{array}\right]
$$

In the same manner as in the previous derivations, the complete model for the governor-turbine can be given as in Figure 3 . 


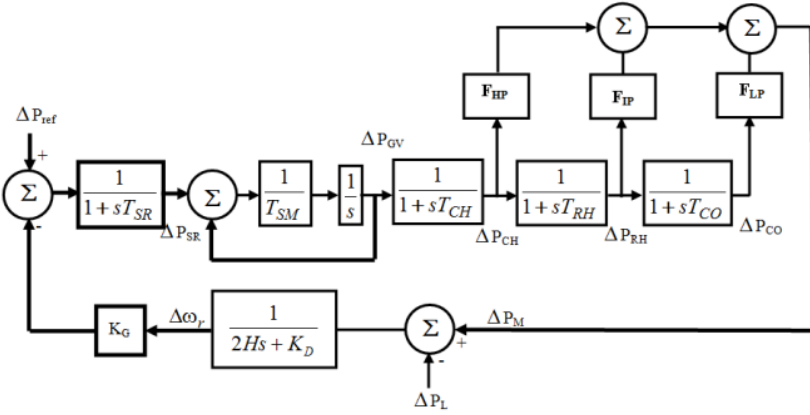

Fig. 3 Governor-turbine model

Also in the vector-matrix form, the governor-turbine system can be given as follows:

$\frac{d}{d t}\left[\begin{array}{c}\Delta \omega_{r} \\ \Delta P_{S R} \\ \Delta P_{G V} \\ \Delta P_{C H} \\ \Delta P_{R H} \\ \Delta P_{C O}\end{array}\right]=\left[\begin{array}{cccccc}\frac{-K_{D}}{2 H} & 0 & 0 & \frac{F_{H P}}{2 H} & \frac{F_{I P}}{2 H} & \frac{F_{L P}}{2 H} \\ \frac{-K_{G}}{T_{S R}} & \frac{-1}{T_{S R}} & 0 & 0 & 0 & 0 \\ 0 & \frac{1}{T_{S M}} & \frac{-1}{T_{S M}} & 0 & 0 & 0 \\ 0 & 0 & \frac{1}{T_{C H}} & \frac{-1}{T_{C H}} & 0 & 0 \\ 0 & 0 & 0 & \frac{1}{T_{R H}} & \frac{-1}{T_{R H}} & 0 \\ 0 & 0 & 0 & 0 & \frac{1}{T_{C O}} & \frac{-1}{T_{C O}}\end{array}\right]\left[\begin{array}{c}\Delta \omega_{r} \\ \Delta P_{S R} \\ \Delta P_{G V} \\ \Delta P_{C H} \\ \Delta P_{R H} \\ \Delta P_{C O}\end{array}\right]+\left[\begin{array}{cc}0 & \frac{-1}{2 H} \\ \frac{1}{T_{S R}} & 0 \\ 0 & 0 \\ 0 & 0 \\ 0 & 0 \\ 0 & 0\end{array}\right]\left[\begin{array}{c}\Delta P_{r e f} \\ \Delta P_{L}\end{array}\right]$

\section{PERFORMANCE EVALUATION OF DESIGN THE CONVENTIONAL AVR \& GOVERNOR}

The mathematical model, which represents the exciter-generator and the governor-turbine, has been programmed using MATLAB 7.0 programming language.

It can be seen that from (6), which represent the model, that $K A$ is a regulator or amplifier as shown in Figure 2.

The input will be taken to be as the $V_{\text {ref. }}$ only, assuming $\Delta P_{m}=0$ (i.e. constant, there is no change in the mechanical power).

The output in the state-space can be taken arbitrary, for this model the terminal voltage $\Delta E_{t}$ is taken to be an output and can be given as:

$\Delta E_{t}=K_{5} \Delta \delta+K_{6} \Delta E^{\prime}$

or in state-space

$$
\Delta E_{t}=\left[\begin{array}{llll}
0 & K_{5} & K_{6} & 0
\end{array}\right]\left[\begin{array}{c}
\Delta \omega_{r} \\
\Delta \delta \\
\Delta E^{\prime} \\
\Delta E_{f d}
\end{array}\right]
$$

Changing the value of $K A$, and for these changes evaluating the values of the $K_{S}, K_{D}$, and the time domain specifications evaluated are shown in Table1.

$K_{S}, K_{D}$ can be given as follows:

$\omega_{n}=\sqrt{K_{S} \frac{\omega_{o}}{2 H}} \mathrm{rad} / \mathrm{s}$
And the damping ratio is

$\zeta=\frac{1}{2} \frac{K_{D}}{2 H \omega_{n}}=\frac{1}{2} \frac{K_{D}}{\sqrt{K_{S} 2 H \omega_{o}}}$

In specifying the transient-response characteristics of a control system to a unit-step input, it is common to name the; Delay time, $t_{d}$; Rise time, $t_{r}$; Peak time, $t_{p}$; Maximum overshoot, $M_{P}$ and Settling time, $t_{\mathrm{s}}$.

TABLE 1 CONVENTIONAL AVR

\begin{tabular}{|c|c|c|c|c|c|c|c|c|}
\hline $\mathrm{KA}$ & $\omega_{\mathrm{n}}$ & $\mathrm{t}_{\mathrm{s}}$ & $\mathrm{K}_{\mathrm{s}}$ & $\begin{array}{c}\mathrm{K}_{\text {stotal }} \\
\mathrm{K} 1+ \\
\mathrm{K}_{\mathrm{s}}\end{array}$ & $\mathrm{K}_{\mathrm{D}}$ & $\begin{array}{c}\text { Peak } \\
\mathrm{amp} .\end{array}$ & $\mathrm{t}_{\mathrm{p}}$ & $\begin{array}{r}\% \mathrm{M} \\
\mathrm{P}\end{array}$ \\
\hline 1 & 0.37 & 37.2 & 0.002 & 0.766 & 1.39 & 1.43 & 8.64 & 42.2 \\
\hline 10 & 1.2 & 39.8 & 0.026 & 0.791 & 1.35 & 1.78 & 2.58 & 77.8 \\
\hline 20 & 1.71 & 42.5 & 0.054 & 0.818 & 1.29 & 1.86 & 1.92 & 86 \\
\hline 30 & 2.11 & 44.8 & 0.082 & 0.846 & 1.23 & 1.9 & 1.47 & 90.1 \\
\hline 40 & 2.46 & 47.5 & 0.112 & 0.876 & 1.15 & 2.01 & 1.27 & 101 \\
\hline 50 & 2.77 & 51.1 & 0.142 & 0.906 & 1.05 & 2.11 & 1.12 & 111 \\
\hline 60 & 3.08 & 57.3 & 0.176 & 0.940 & 0.94 & 2.19 & 1.08 & 119 \\
\hline 70 & 3.37 & 69.1 & 0.210 & 0.975 & 0.78 & 2.25 & 0.98 & 125 \\
\hline 80 & 3.67 & 96.8 & 0.250 & 1.014 & 0.54 & 2.26 & 0.98 & 134 \\
\hline 90 & 3.99 & 504 & 0.295 & 1.059 & 0.10 & 2.31 & 0.87 & 135 \\
\hline 91 & 4.03 & 1590 & 0.301 & 1.065 & 0.03 & 2.33 & 0.86 & 140 \\
\hline
\end{tabular}

Figure 4 and Figure 5 shows the plotting of the output terminal voltage $E_{t}$ versus $t$ for number of $K A$ values

From the evaluated table and graphs it is shown that the damping is low, and if the gain of the regulator increased then the damping will be less.

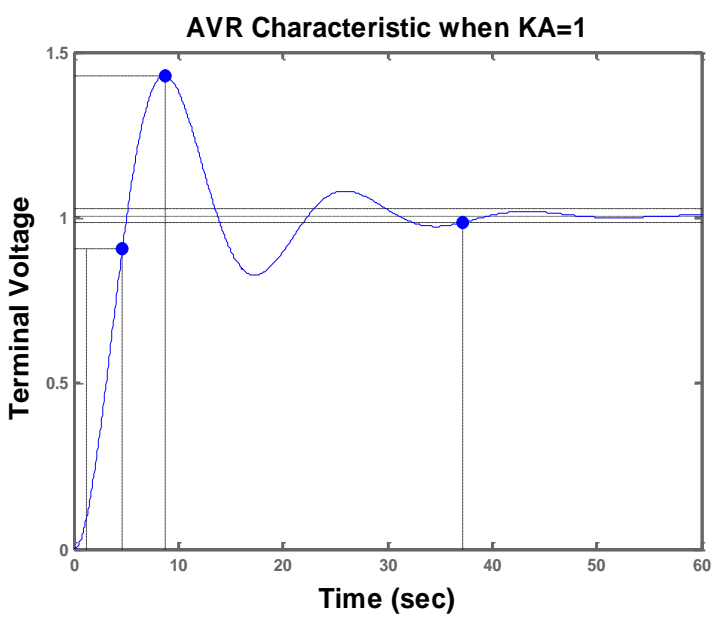

Fig. 4 Terminal voltage of the generator with $\mathrm{KA}=1$ 


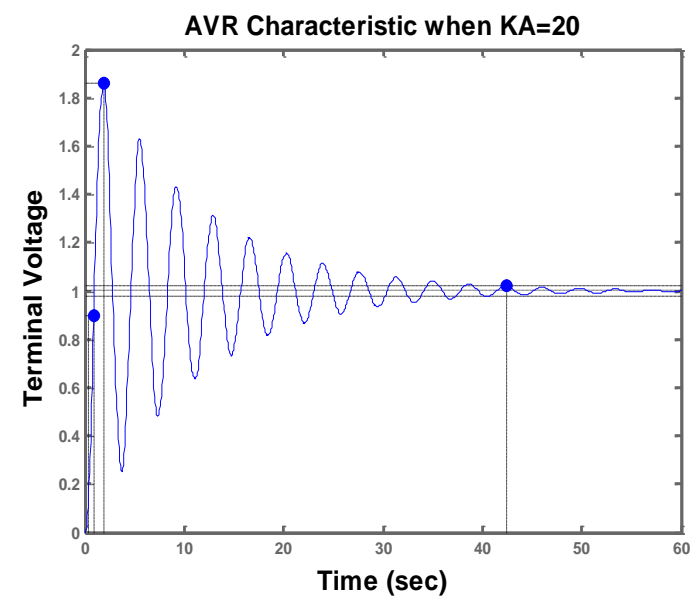

Fig. 5 Terminal voltage of the generator with $K A=20$

It can be also seen that from (7), which represent the governorturbine model, as shown in Fig. 3, the input will be taken to be as the $\Delta P_{l}$, which can be changed as $6 \%, 8 \%, 10 \%$ and $15 \%$ and assuming $\Delta P_{\text {ref. }}=0$. The output will be chosen to be the changes in mechanical power $\Delta P_{m}$ and the frequency response $\Delta \omega_{\mathrm{r}}$ as shown in Figure 6.

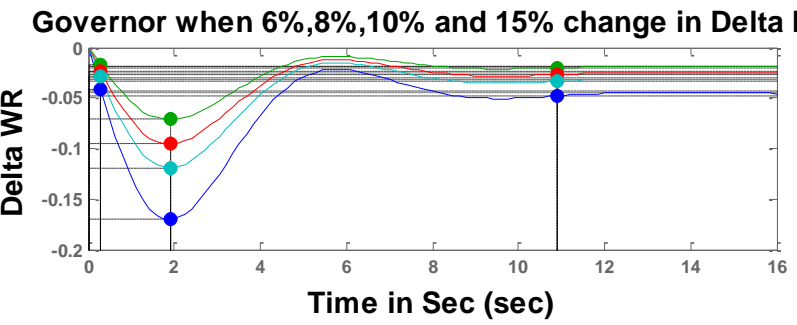

Governor when $6 \%, 8 \%, 10 \%$ and $15 \%$ change in Delta PL

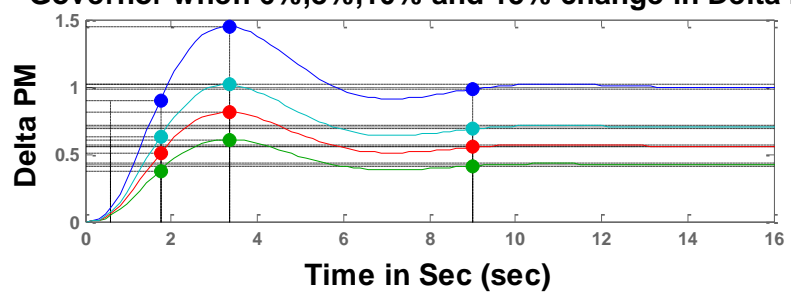

Fig.6 $\Delta \omega_{\mathrm{r}}$ and $\Delta \mathbf{P}_{\mathrm{m}}$ change for all load changes

The time domain specifications from Figure 6 can be given in Table 2 and Table 3.

TABLE 2 TIME DOMAIN SPECIFICATION FOR CONVENTIONAL GOVERNOR FROM $\triangle \omega_{\mathrm{r}}$ GRAPH

\begin{tabular}{|c|c|c|c|c|}
\hline$\% \Delta P_{L}$ & $\mathbf{t}_{\mathbf{s}}$ & $\begin{array}{c}\text { Peak } \\
\text { amp. }\end{array}$ & $\mathbf{t}_{\mathbf{p}}$ & $\mathbf{\%}_{\mathbf{P}}$ \\
\hline 6 & 10.9 & -0.0715 & 1.92 & 275 \\
\hline 8 & 10.9 & -0.0953 & 1.92 & 275 \\
\hline 10 & 10.9 & -0.119 & 1.92 & 275 \\
\hline 15 & 10.9 & -0.17 & 1.92 & 275 \\
\hline
\end{tabular}

International Journal of Computer Applications (0975 - 8887)

Volume 85 - No 12, January 2014

TABLE 3 TIME DOMAIN SPECIFICATION FOR CONVENTIONAL GOVERNOR FROM $\triangle \mathrm{P}_{\mathrm{m}}$ GRAPH

\begin{tabular}{|c|c|c|c|c|}
\hline$\% \Delta P_{L}$ & $\mathbf{t}_{\mathbf{s}}$ & $\begin{array}{c}\text { Peak } \\
\text { amp. }\end{array}$ & $\mathbf{t}_{\mathbf{p}}$ & $\mathbf{\%} \mathbf{M}_{\mathbf{P}}$ \\
\hline 6 & 9 & 0.608 & 3.36 & 44.8 \\
\hline 8 & 9 & 0.811 & 3.36 & 44.8 \\
\hline 10 & 9 & 1.01 & 3.36 & 44.8 \\
\hline 15 & 9 & 1.45 & 3.36 & 44.8 \\
\hline
\end{tabular}

\section{LQG CONTROLLER DESIGN BASED ON SEPARATION PRINCIPLE}

The following steps give the design procedure followed in the design of the LQG controller given in Figure 7 that used here. $[11,12,13$ and 14]

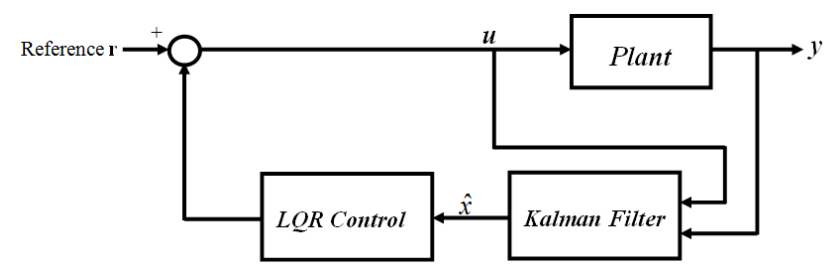

Fig. 7 Block Diagram of the Proposed LQG Control Law

- Design the (Linear Quadratic Regulator) LQR control law $u=-K x$ which solves the following Problem, $\dot{x}=A x+B u$,

$$
\left.J_{(x, u, Q, R)}=\int_{0}^{\infty}\left(x^{T} Q x+R u^{2}\right) d t, Q \geq 0, R\right\rangle 0
$$
i.e., compute

$$
\begin{gathered}
\left.A^{T} P+P A-P B R^{-1} B^{T} P+Q=0, P\right\rangle 0, \\
K=R^{-1} B^{T} P
\end{gathered}
$$

- Design a Kalman filter for the given plant, i.e.,

$$
\begin{gathered}
\dot{\hat{x}}=A \hat{x}+B u+K_{e}(y-\hat{y}), \\
\hat{y}=C \hat{x}, \text { where } \\
\left.P_{e} A^{T}+A P_{e}+Q-P_{e} C^{T} R^{-1} C P_{e}=0, P_{e}\right\rangle 0, \\
K_{e}=P_{e} C^{T} R^{-1}
\end{gathered}
$$

- The LQG control law is given by $\boldsymbol{u}=-\boldsymbol{K} \hat{x}$, i.e.,

$$
\left\{\begin{array}{c}
\dot{\hat{x}}=A \hat{x}+B u+K_{e}(y-C \hat{x}) \\
u=-K \hat{x}
\end{array}\right.
$$

Then,

$$
\left\{\begin{array}{c}
\dot{\hat{x}}=\left(A-K B-K_{e} C\right) \hat{x}+K_{e} y \\
u=-K \hat{x}
\end{array}\right.
$$

Designing the second controller for the 2DOF LQG which is the integrator 


\section{TWO DEGREE OF FREEDOM LQG CONTROLLER}

For the (2DOF), consider the system shown in Figure 8, where $G_{P}(\mathrm{~s})$ is the transfer function of the plant, for this system, closed loop transfer function $G_{y r}, G_{y n}$, and $G_{y d}$ are given respectively as follows:[15, 16 and 17]

$$
\begin{aligned}
& G_{y r}=\frac{Y(s)}{R(s)}=\frac{G_{C 1} G_{P}}{1+\left(G_{C 1}+G_{C 2}\right) G_{P}}, \\
& G_{y d}=\frac{Y(s)}{D(s)}=\frac{G_{P}}{1+\left(G_{C 1}+G_{C 2}\right) G_{P}}, \\
& G_{y n}=\frac{Y(s)}{N(s)}=\frac{-\left(G_{C 1}+G_{C 2}\right) G_{P}}{1+\left(G_{C 1}+G_{C 2}\right) G_{P}}
\end{aligned}
$$

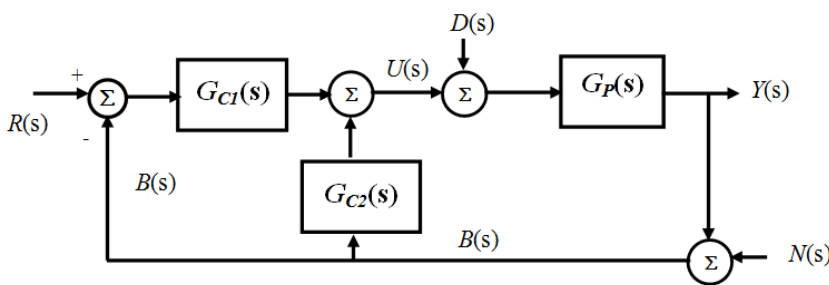

Fig. 8 Two Degree of Freedom Control System

Hence,

$$
G_{y r}=G_{C 1} G_{y d}, G_{y n}=\frac{G_{y d}-G_{P}}{G_{P}}
$$

In this case if $G_{y d}$ is given, then $G_{y n}$ is fixed, but $G_{y r}$ is not fixed, because $G_{C l}$ is independent $G_{y d}$. Thus, two closed loop transfer functions among three closed loop transfer functions $G_{y r}, G_{y n}$, and $G_{y d}$ are independent. Hence, this system is two degrees of freedom control system.

It will be seen in such a two degree of freedom control system, both the closed loop characteristics and the feedback characteristics can be adjusted independently to improve the system response performance.

The strategy used in this work is to design the proposed two degree of freedom LQG and including an integrator action as shown in Figure 9 (i.e. first controller is LQG and the second controller is the integrator). The integral control of the system eliminates the steady state error in the response to the step input.

Under integral control action the control signal (the output signal from the controller) at any instant is the area under the actuating error signal curve up to that instant. The control signal can have a nonzero value when the actuating error signal $(r-y)$ is zero.

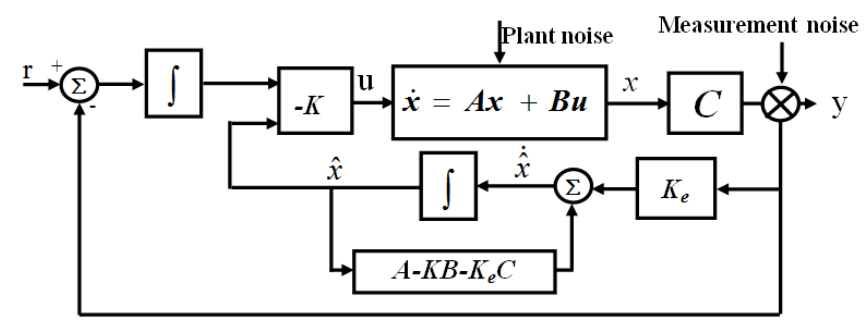

Fig. 9 Two Degree of Freedom LQG

\section{PERFORMANCE EVALUATION OF DESIGN THE PROPOSED 2DOFLQG AVR \& GOVERNOR}

Designing the AVR using the 2DOFLQG gives the values of $K_{S}$ and $K_{D}$ and the time domain specifications which are given in Table 4.

TABLE 4 AVR USING 2DOFLQG

\begin{tabular}{|c|c|c|c|c|c|c|c|}
\hline $\boldsymbol{\omega}_{\mathbf{n}}$ & $\mathbf{t}_{\mathbf{s}}$ & $\mathbf{K}_{\mathbf{s}}$ & $\begin{array}{c}\mathbf{K}_{\text {stotal= }} \\
\mathbf{K 1}+\mathbf{K}_{\mathbf{s}}\end{array}$ & $\mathbf{K}_{\mathbf{D}}$ & $\begin{array}{c}\text { Peak } \\
\mathbf{a m p .}\end{array}$ & $\mathbf{t}_{\mathbf{p}}$ & $\boldsymbol{\%} \mathbf{M}_{\mathbf{P}}$ \\
\hline 1.12 & 5.92 & 0.023 & 0.7875 & 7.949 & 1.08 & 4.46 & 8.04 \\
\hline
\end{tabular}

Figure 10 shows the plotting of the output terminal voltage $E_{t}$ versus $t$. What is obvious in this technique is the value of the damping torque, which is still high, and the time domain specification (control performance) is enhanced due to the effect of using the LQG controller and the integral controller.

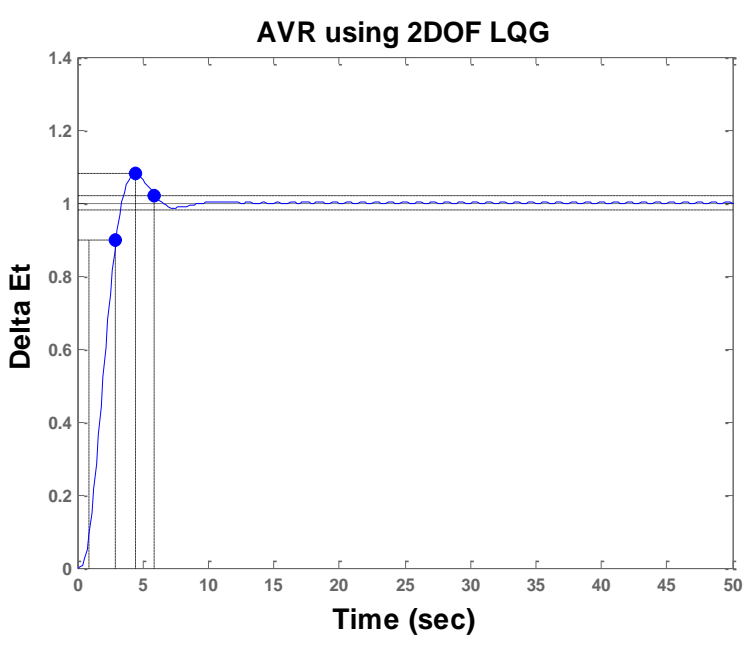

Fig. 10 Terminal voltage of the generator with 2DOF LQG AVR

Designing the Governor using 2DOFLQG gives the time domain specifications shown in Table 5. 
TABLE 5 TIME DOMAIN SPECIFICATION FOR 2DOFLQG GOVERNOR FROM $\Delta \omega_{\mathrm{r}}$ GRAPH

\begin{tabular}{|c|c|c|c|c|c|}
\hline$\% \Delta P_{L}$ & $\mathrm{t}_{\mathrm{s}}$ & $\mathrm{t}_{\mathrm{r}}$ & $\begin{array}{l}\text { Peak } \\
\text { amp. }\end{array}$ & $\mathrm{t}_{\mathrm{p}}$ & $\% \mathrm{M}_{\mathrm{P}}$ \\
\hline 6 & 2.69 & 0.043 & -0.017 & 0.66 & 464 \\
\hline 8 & 2.7 & 0.033 & -0.018 & 0.6 & 518 \\
\hline 10 & 2.94 & 0.026 & -0.020 & 0.48 & 567 \\
\hline 15 & 2.94 & 0.019 & -0.023 & 0.42 & 661 \\
\hline
\end{tabular}

TABLE 6 TIME DOMAIN SPECIFICATION FOR 2DOFLQG GOVERNOR FROM $\triangle \mathbf{P}_{\mathrm{m}}$ GRAPH

\begin{tabular}{|c|c|c|c|c|c|}
\hline$\% \Delta P_{L}$ & $\mathrm{t}_{\mathrm{s}}$ & $\mathrm{t}_{\mathrm{r}}$ & $\begin{array}{c}\text { Peak } \\
\text { amp. }\end{array}$ & $\mathrm{t}_{\mathrm{p}}$ & $\% \mathrm{M}_{\mathrm{P}}$ \\
\hline 6 & 3.59 & 0.539 & 0.101 & 1.68 & 52 \\
\hline 8 & 3.58 & 0.481 & 0.104 & 1.5 & 55.5 \\
\hline 10 & 3.68 & 0.442 & 0.106 & 1.38 & 58.1 \\
\hline 15 & 3.76 & 0.389 & 0.109 & 1.26 & 62 \\
\hline
\end{tabular}

Figure 11 shows the plotting of $\Delta \omega_{r}$ and $\Delta \mathrm{P}_{\mathrm{m}}$ for $6 \%, 8 \%$, $10 \%$ and $15 \%$ of $\Delta P_{L}$ change versus $t$ on the same graph. As seen also the integral action has been enhanced the time domain specifications (control performance).

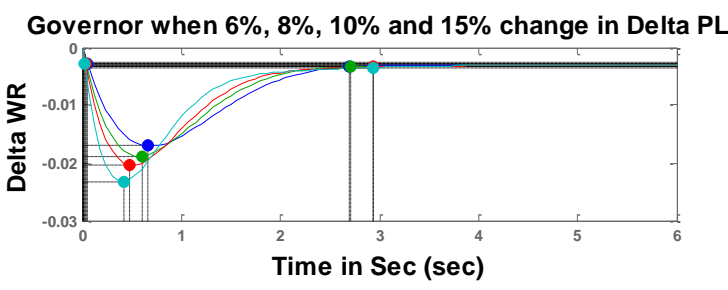

Governor when $6 \%, 8 \%, 10 \%$ and $15 \%$ change in Delta PL

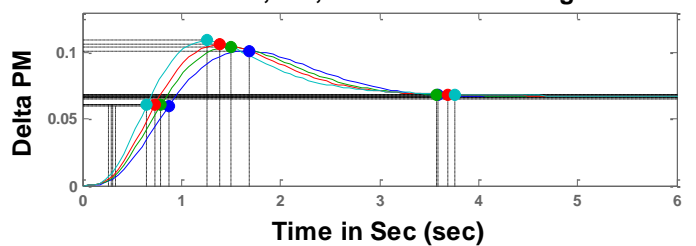

Fig. $11 \Delta \omega_{r}$ and $\Delta P_{m}$ change for $6 \%, 8 \%, 10 \%$ and $15 \%$ of the load change using 2DOFLQG Governor

\section{CONCLUSION}

In this paper a controller based on a two degree of freedom Linear Quadratic Gaussian (2DOFLQG) designed to control the generator voltage via the AVR and the turbine speed via the governor, this controller has been compared with the conventional one. The plant noise and the measurement noise were considered. This technique which depends on the 2DOFLQG gives best damping torque, synchronizing torque and time domain specification with comparison with the conventional techniques, shown clearly in Tables $(1,2,3,4,5$ and 6 which leads to improving the stability of the whole system.

\section{REFERENCES}

[1] Michael J. Basler and Richard C. Schaefer: Understanding Power System Stability, Basler Electric Company, IEEE 2005.
[2] P.Kundor: power system stability and control, McGrawHill, Inc, 1994.

[3] R. Asgharian and D.C. Macdonald "the design of turbinegenerator optimal controllers including the effect of torsional modes of oscillation" IEEE Transactions on Energy Conversion, Vol. 3, No. 2, June 1988, pp.230-234

[4] Ranjan Vepa "Nonlinear, Optimal Control of a Wind Turbine Generator" IEEE Transactions on Energy Conversion, Vol. 26, No. 2, June 2011, pp.468-478.

[5] Youssef A. Smailli and Ali T. Alouani“An $\mathrm{H}_{\text {infinity }}$ governor exciter controller design for a power system" First IEEE Conference on control applications, Vol.2, 1992, pp.770-775.

[6] M. Djukanovic et. al. "neural-net based coordinated stabilizing control for the exciter and governor loops of low head hydropower plants" IEEE Transactions on Energy Conversion, Vol. 10, No. 4, December 1995 , pp.760-767.

[7] F. Fatehi et.al. "robust power system controller design based on measured models" IEEE Transactions on Power Systems, Vol. 11, No. 2, May 1996, pp.774-780.

[8] Gui-chen ZHANG“Augmented LQG optimal control of dynamic performance for ETG system" International Conference on Artificial Intelligence and Computational Intelligence, 2009

[9] E. A. Feilat and N. Younan" on-line adaptive assessment of the synchronizing and damping torque coefficients using Kalman filtering" Southeastcon '99. Proceedings IEEE publisher, 1999, pp.145-148.

[10] T. C. Yang and H. Cimen: Applying Structured Singular Values and a New LQR Design to Robust Decentralized Power System Load Frequency Control, Proceedings of The IEEE International Conference on Industrial Technology, 1996.

[11] Peter Dorato, Chaoyki T.Abdallah and Vito Cerone: Linear Quadratic Control An Introduction; Krieger Publishing Company 2000.

[12] Wook Hyun Kwon and Soo Hee Han: Receding Horizon Predictive Control; Prentice Hall, Nov. 2, 2003.

[13] M. J. Grimble :Robust Industrial Control Systems Optimal Design Approach for Polynomial Systems; John Wiley \& Sons, Ltd 2006.

[14] S.Skogested and I.Postlethwaite: Multivariable Feedback Control: Analysis and Design second edition; John Wiley \& Sons, Ltd, 2005.

[15] Katsuhiko Ogata: System Dynamics; Prentice Hall International, Inc. Third Edition 1998.

[16] Katsuhiko Ogata: Modern Control Engineering; Prentice Hall International, Inc. Fourth Edition 2002.

[17] Richard C. Dorf and Robert H. Bishop: Modern Control Systems; Pearson Prentice Hall, 2005. 


\section{APPENDIX A}

\section{GENERATOR}

\begin{tabular}{|c|c|}
\hline S(Apparent power) & $555 \mathrm{MVA}$ \\
\hline $\mathrm{P}$ (Active power) & 0.9 p.u. \\
\hline Q (Reactive Power) & 0.3 p.u(overexcited) \\
\hline $\mathrm{E}_{\mathrm{t}}($ Terminal voltage $)$ & $24 \mathrm{kV}$ or 1 p.u. \\
\hline Speed & $50 \mathrm{~S}^{-1}$ \\
\hline Frequency & $50 \mathrm{HZ}$ \\
\hline $\begin{array}{l}\mathrm{E}_{\mathrm{B}} \text { (Infinite bus } \\
\text { voltage) }\end{array}$ & 0.995 p.u. \\
\hline Connection & Y \\
\hline $\mathrm{H}$ & 3.5 MW.s/MVA \\
\hline$K_{D}$ & 0 \\
\hline $\mathrm{K}_{1}$ & 0.7643 p.u. \\
\hline $\mathrm{K}_{2}$ & 0.8649 p.u. \\
\hline $\mathrm{K}_{3}$ & 0.323 p.u. \\
\hline $\mathrm{K}_{4}$ & 1.4187 p.u. \\
\hline $\mathrm{K}_{5}$ & -0.1463 p.u. \\
\hline $\mathrm{K}_{6}$ & 0.4168 p.u. \\
\hline $\mathrm{T}_{3}$ & $2.365 \mathrm{~s}$ \\
\hline \multicolumn{2}{|l|}{ EXCITER } \\
\hline KA & 30 \\
\hline $\mathrm{T}_{\mathrm{R}}$ & $0.02 \mathrm{~s}$ \\
\hline $\mathrm{K}_{\mathrm{E}}$ & -0.02 \\
\hline $\mathrm{T}_{\mathrm{E}}$ & 0.56 \\
\hline \multicolumn{2}{|l|}{ TURBINE } \\
\hline $\mathrm{KG}$ & $20 \mathrm{MW} / \mathrm{Hz}$ \\
\hline $\mathrm{F}_{\mathrm{HP}}$ & 0.3 \\
\hline $\mathrm{F}_{\mathrm{IP}}$ & 0.4 \\
\hline $\mathrm{F}_{\mathrm{LP}}$ & 0.4 \\
\hline $\mathrm{T}_{\mathrm{SR}}$ & $0.1 \mathrm{~s}$ \\
\hline $\mathrm{T}_{\mathrm{SM}}$ & $0.3 \mathrm{~s}$ \\
\hline $\mathrm{T}_{\mathrm{CH}}$ & $0.18 \mathrm{~s}$ \\
\hline $\mathrm{T}_{\mathrm{RH}}$ & $7 \mathrm{~s}$ \\
\hline $\mathrm{T}_{\mathrm{CO}}$ & $0.4 \mathrm{~s}$ \\
\hline
\end{tabular}

